Article

\title{
Surface Modification of Porous Titanium Discs Using Femtosecond Laser Structuring
}

\author{
Ángel Rodríguez ${ }^{1, * \mathbb{C}}$, Paloma Trueba ${ }^{2}$, José Manuel Amado ${ }^{1}$, María José Tobar ${ }^{1}{ }^{\circledR}$, \\ Mercè Giner $^{3}$ (D), Vicente Amigó ${ }^{4}$ (D) and Yadir Torres ${ }^{2}$ (D) \\ 1 Escuela Politécnica Superior, Universidade da Coruña, Mendizábal s/n, E-15403 Ferrol, Spain; \\ jose.amado.paz@udc.es (J.M.A.); maria.jose.tobar@udc.es (M.J.T.) \\ 2 Departamento de Ingeniería y Ciencia de los Materiales y del Transporte, Escuela Politécnica Superior, \\ Calle Virgen de África, 7, 41011 Sevilla, Spain; ptrueba@us.es (P.T.); ytorres@us.es (Y.T.) \\ 3 Departamento de Citología e Histología Normal y Patológica, Universidad de Sevilla, Avda Dr.Fedriani s/n, \\ 41009 Sevilla, Spain; mginer@us.es \\ 4 Instituto de Tecnología de Materiales, Universitat Politècnica de València, Ciudad Politécnica \\ de la Innovación, Carrer de l'Enginyer Fausto Elio, s/n, 46022 València, Spain; vamigo@mcm.upv.es \\ * Correspondence: angel.rcarballo@udc.es; Tel.: +34-981-337-400
}

Received: 6 May 2020; Accepted: 2 June 2020; Published: 4 June 2020

\begin{abstract}
The failure of titanium implants is associated with two main problems that include the bone resorption and fracture of the surrounding bone tissue (stiffness incompatibility) and implant loosening (poor osseointegration). The development of porous titanium implants with low Young modulus solve the stress shielding phenomenon, while the modification of the implant surface must be implemented to promote a fast bond between the implant and bone. In this work, femtosecond laser micromachining was applied to modify the topography of the surface of Ti porous samples obtained by a space-holder technique to obtain hierarchical structures (micro and nano roughness patterns) to enhance osseointegration. Scanning electron microscopy, confocal laser microscopy, and image analysis were used for characterization of the surface morphology, roughness, and porosity before and after performing the laser treatment. Based on these results, the effect of the treatment on the mechanical behavior of the samples was estimated. In addition, a preliminary in-vitro test was performed to verify the adhesion of osteoblasts (filopodia presence) on modified titanium surface. Results revealed that laser texturing generated clusters of micro-holes and micro-columns both on the flat surface of the samples and inside the macro-pores, and periodic nanometric structures across the entire surface. The porous substrate offers suitable biomechanics (stiffness and yield strength) and bio-functional behavior (bone ingrowth and osseointegration), which improves the clinic success of titanium implants.
\end{abstract}

Keywords: porous titanium; femtosecond; roughness patterns; surface modification; osseointegration

\section{Introduction}

Currently, the manufacturing of bone implants is a field of increasing importance within the medical sector. Due to the progressive aging of the population, there is an increase in the demand for reliable implants. Among metallic biomaterials for orthopedic and dental implants, titanium and its alloys constitute an excellent choice thanks to their superior mechanical properties, high corrosion resistance, and excellent biocompatibility [1,2]. However, there are currently two main problems that compromise their use as implant materials: bone resorption of the tissue surrounding the implant associated with the phenomenon of stress shielding due to the difference between the Young modulus of the alloy and that of the cortical bone tissue [3-5]; and the problems at the interface of the implant (implant loosening, proliferation of bacteria, etc.) associated with poor osseointegration [6,7]. 
The need to solve the problem of stress shielding has led to the development of $\beta$ titanium alloys with low elastic modulus. These alloys are based on refractory alloy elements of low toxicity for cells (such as $\mathrm{Nb}, \mathrm{Mo}, \mathrm{Zr}$, and $\mathrm{Ta}$ ) and, therefore, they present excellent biocompability $[8,9]$. In recent decades, several studies have addressed the problem of stress shielding by designing and manufacturing porous materials with lower Young modulus [10-12]. The morphologies and size of the pores, the percentage of porosity, and the degree of interconnectivity of the porous structure play an important role in bone tissue formation throughout the implant $[13,14]$. However, so far, there is no consensus on the optimal pore diameter and percentage of porosity to maximize bone ingrowth $[15,16]$. In addition, pores larger than 100 microns ensure bone ingrowth requirements. However, excessive pore size and content as well as deficient sinterability (quality of the necks) may compromise fracture and fatigue behavior.

To achieve good osseointegration, it is important that the implant surface promotes adhesion, proliferation, and differentiation of tissue cells (bone) [17,18]. At the same time, it is desirable to prevent the adhesion and proliferation of bacteria at the interface, which could cause infections and failure of the implant. In order to accomplish this goal, multiple techniques have been studied to modify the properties of the surface. These techniques can be divided in two main groups: chemical modifications and physical modifications [19]. Chemical techniques consist of coating or impregnating the surface with elements that encourage the interaction between the implant material and tissue cells and promote bone growth. The coatings are usually made of bioactive materials such as hydroxyapatite or bio-glass [20]. Physical methods are comprised of techniques focused on modifying the topography of the surface. Within these groups, there are many techniques capable of creating surface structures on implants such as grit-blasting, acid-etching, plasma spray, or laser surface processing [21,22].

Several studies showed that surfaces containing micrometric roughness improve osseointegration when compared to smooth surfaces [23-26]. Surface microstructures promote osteogenic differentiation (better differentiation, less proliferation with more roughness) $[27,28]$ and mechanical interlocking between the implant and the bone [29-31]. Currently, surface micro-roughening has already become a standard technique and, therefore, many commercial implants undergo a process of some kind to increase the roughness of the surface.

In more recent times, the effect that roughness at the nanometric level could have on the performance of the implant at the interface has begun to be studied. Although not yet fully understood, it is believed that cellular behavior can be modified by the topography at the nanometric level [32-37]. It has been suggested that the ability of nano-scaled structures to mimic bone structures lies behind the improvement in bone cell behavior during osseointegration [38,39]. Moreover, roughness and features at the nano-scale level can have great influence on the wettability of the surface, which, in turn, can affect cell adhesion [40]. To better understand the interaction between these types of structures and the host tissue, it is important to use techniques capable of generating repeatable and controllable periodic structures at the nanometric level [41].

Several studies have raised the possibility that the use of a multiscale hierarchical structure composed of micro-features and nano-features could enhance osseointegration with respect to only nanometric or micrometric structures. Gittens et al. obtained increased osteoblast differentiation and local production by introducing nanoscale structures over titanium micro-rough surfaces [42]. Huang et al. observed that different types of nano-features over a micro-topographical surface can have different effects in cell functions [43]. Zhao et al. compared the osteoblasts' behavior on a micro-structured titanium surface prepared by acid etching and on a hierarchical micro-nanostructured titanium surface prepared by acid etched plus anodization to form nano-textures [44]. They found that the micro-structured surface increased cell adhesion but also reduced cell proliferation. Instead, the hierarchical structure allowed retaining or increasing most of the cell functions studied. Ferraris et al. combined a chemical treatment with a dual acid etching process to obtain a micro-nano-texture on the surface of dental implants [45]. The treated samples showed enhanced protein absorption, bioactivity, and hydrophilicity when compared with traditional dual acid etching samples. 
Among the existing techniques used to obtaining hierarchical structures is the laser structuring technique. Laser structuring is a promising technique that presents advantages over other conventional structuring techniques. This process is fast, contactless, and clean. It can be applied in ambient air and it has high precision $[46,47]$.

Laser structuring of titanium is most commonly done using femtosecond laser systems. By using ultrashort laser pulses instead of nanosecond laser pulses, high quality surface structures can be obtained due to the minimal heat affected zone and thermal damage on the workpiece [48]. Femtosecond laser micromachining allows us to obtain a great variety of surface structures, ranging from a nanoscale to a microscale size, such as laser-induced periodic surface structures (LIPSS), undulating grooves, and columnar, hole, or maze structures [49]. The processing parameters must be carefully selected in order to attain the desired structure [50].

Hierarchical multiscale structures in which the microstructures are covered by nanostructures can also be realized by laser processing [51,52]. These composite micro-nano-textures have been shown their ability to modify the behavior of the cells [53-57] and to change the wettability of the surface $[58,59]$. Additionally, by carefully controlling the size of the obtained structures, the adhesion and proliferation of bacterial cells can be inhibited [60].

In this work, femtosecond laser micromachining has been applied to porous titanium samples manufactured by the space-holder technique. The goal is to obtain a hierarchical nano-micro-structure in which a self-organized nanostructure consisting of LIPSS is generated on top of micro pillars distributed along the surface of the sample. This hierarchical structure is created both inside the pores generated by the space-holder technique and on the flat surface of the samples. Therefore, when using this methodology, a three-level hierarchical topography is generated. It is composed of big macro-pores from the space-holder technique and small micro-pores and a nano-texture from the laser treatment. The samples have been analyzed in terms of surface morphology, roughness, and porosity and the surface structures have been compared before and after the femtosecond laser treatment. Additionally, an estimation of the mechanical behaviour of the porous samples is included. A preliminary in vitro study evaluates the potential capacity to improve cell adhesion of the proposed treatments.

\section{Materials and Methods}

\subsection{Obtention of the Porous Titanium Samples}

In this work, different commercially pure titanium (Ti CP-Grade IV) discs were manufactured.

Figure 1 shows a schematic diagram explaining how the samples were prepared. On the one hand, a fully-dense sample was produced by conventional powder metallurgy, pressing and sintering the powder at $1300 \mathrm{MPa}$ and $1300{ }^{\circ} \mathrm{C}$, respectively. On the other hand, porous samples were obtained by the space-holder technique by mixing the titanium powder with $50 \%$ vol. of spacer $\left(\mathrm{NH}_{4} \mathrm{HCO}_{3}\right)$. Two ranges of spacer size were chosen for the study: 100-200 $\mu \mathrm{m}$ and 355-500 $\mu \mathrm{m}$. Then, the mixture was pressed at $800 \mathrm{MPa}$. Subsequently, the $\mathrm{NH}_{4} \mathrm{HCO}_{3}$ was removed in a low vacuum furnace (Heraeus, Hanau, Germany) $\left(10^{-2} \mathrm{mbar}\right)$ in two stages $\left(60^{\circ} \mathrm{C}\right.$ and $\left.110^{\circ} \mathrm{C}\right) 12 \mathrm{~h}$ each. Lastly, the porous green samples were sintered at $1250{ }^{\circ} \mathrm{C}$. Both sinters were carried out in a ceramic furnace $\left(\right.$ Carbolyte ${ }^{\circledR}$ STF 15/75/450, Carbolyte Gero Ltd., Hope, UK) under high vacuum atmosphere ( 10 ${ }^{-5}$ mbar $)$ for $2 \mathrm{~h}$. Before performing the surface modification, a conventional and careful metallographic preparation of the specimen was necessary to preserve the porosity fraction, size, and morphology of the pores. This process included resin mounting, grinding, and mechano-chemical polishing with magnesium oxide $(\mathrm{MgO})$ and hydrogen peroxide $\left(\mathrm{H}_{2} \mathrm{O}_{2}\right)$. 


\section{$\underline{\text { Titanium substrates with a Hierarchical Nano-Micro- Structure }}$}

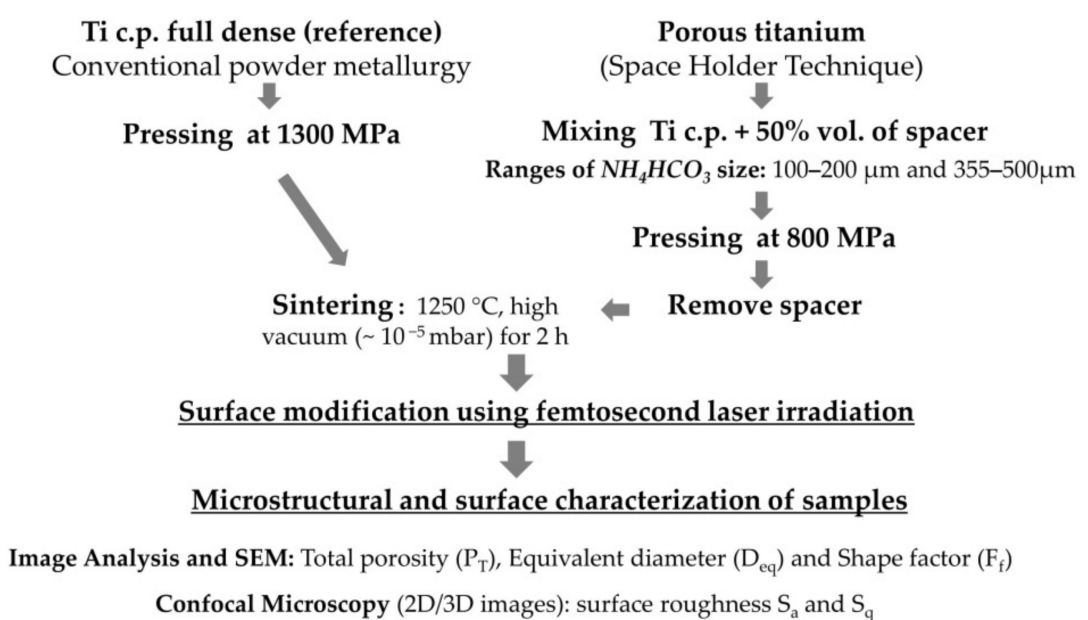

Figure 1. Schematic diagram of the experimental setup.

\subsection{Surface Modification Using Femtosecond Laser Irradiation}

Femtosecond laser irradiation was performed using a Yb-doped fiber laser (Spirit 1040-4, Spectra-Physics, Santa Clara, CA, USA) with a wavelength of $1040 \mathrm{~nm}$ and $396 \mathrm{fs}$ pulses at a repetition rate of $\mathrm{f}=100 \mathrm{kHz}$ with a maximum pulse energy of $49.7 \mu \mathrm{J}$. The experimental setup is shown in Figure 2. After deflection by a galvanometer scanner, the laser beam is focused through a F-Theta lens $(\mathrm{f}=160 \mathrm{~mm})$ to a beam radius of approximately $\mathrm{w}_{0}=12 \mu \mathrm{m}$ on the working surface. As shown in the diagram of Figure $2 b$, the surface of the samples was scanned line by line with the moving laser beam and the laser paths were separated from each other according to a specified overlap. The surface can be processed multiple times to increase the energy deposited on the surface. The experiments were performed in air, and Argon was used as shielding gas in order to reduce any undesirable oxidation on the surface of the workpiece. A nozzle placed on the side of the part directed the jet of shielding gas over the surface to be processed. Macroscopic images of the samples revealed that the use of shielding gas was satisfactory since there was no visible oxidation on the processed surfaces.



Figure 2. Experimental setup for femtosecond laser processing. (a) Components of the laser system and (b) illustration of the laser texturing process. 
Preliminary experiments were carried out to determine the optimal processing parameters. The selection of the parameters was made on the basis that the main goal was to achieve the combination of two laser-induced structures on the surface of the workpiece, which include laser-induced periodic surface structures (LIPSS), also known as ripples, and columnar micro structures/micro pillars. A parametric study was performed by changing the values of laser power, scanning speed, and number of repetitions (the number of times the surface was scanned). Modifying these parameters allowed regulating the energy deposited on the surface and the number of laser spots per unit area, which have a great influence on the surface structures obtained. The distance between consecutive lines was fixed for each experiment so that the distance between laser spots in the direction parallel and perpendicular to the scanning direction was similar. Scanning electron microscopy (SEM) images of the processed surfaces were analyzed in order to choose the final parameters, which are reported in Table 1. A pulse energy of $E_{p}=49.7 \mu \mathrm{J}(100 \%$ nominal power $)$ and a scanning speed of $\mathrm{v}=960 \mathrm{~mm} / \mathrm{s}$ were chosen. The resultant fluence was $\mathrm{F}=21.98 \mathrm{~J} / \mathrm{cm}^{2}$. The distance between parallel lines was set to $\mathrm{d}=12 \mu \mathrm{m}$, corresponding to a spot overlap between lines of $\mathrm{s}=50 \%$. The area was scanned $\mathrm{Nr}=20$ times using these parameters. Under these conditions, the resultant number of pulses per spot (PPS) on the surface was PPS $=100$.

Table 1. Laser parameters.

\begin{tabular}{|c|c|}
\hline Wavelength & $1040 \mathrm{~nm}$ \\
\hline Pulse duration & $396 \mathrm{fs}$ \\
\hline Repetition rate (f) & $100 \mathrm{kHz}$ \\
\hline Maximum pulse energy $\left(E_{p}\right)$ & $49.7 \mu \mathrm{J}$ \\
\hline Spot radius $\left(\mathrm{w}_{0}\right)$ & $12 \mu \mathrm{m}$ \\
\hline Scanning speed $(\mathrm{v})$ & $960 \mathrm{~mm} / \mathrm{s}$ \\
\hline Distance between consecutive lines (d) & $12 \mu \mathrm{m}$ \\
\hline Number of repetitions $(\mathrm{Nr})$ & 20 \\
\hline
\end{tabular}

\subsection{Microstructural and Surface Characterization of Samples}

The porosity of the samples was evaluated by image analysis (IA) using a Nikon Epiphot optical microscope (Nikon, Tokyo, Japan) coupled with a Jenoptik Progres C3 camera (Jenoptik, Jena, Germany) and Image-Pro Plus 6.2 analysis software. Total porosity $\left(\mathrm{P}_{\mathrm{T}}\right)$, equivalent diameter $\left(\mathrm{D}_{\mathrm{eq}}\right)$, and shape factor $F_{f}$ were measured. The shape factor was defined as $F_{f}=4 \pi A /(P E)^{2}$, where $A$ is the area of the pore and $\mathrm{PE}$ is its experimental perimeter. Image analysis was assessed using five pictures of $5 x$ for each sample (one for each kind of material).

Scanning electron microscopy (FEI Teneo, FEI, Eindhoven, The Netherlands) and confocal laser scanning microscopy (Sensofar Sneox, Sensofar, Glonn, Germany, allowing 2D and 3D images) were used to evaluate the size and morphology of pores and surface roughness patterns resulting from substrate fabrication using the spacers' technique and the superficial modification with femtosecond laser irradiation. In addition, the confocal laser scanning microscopy was performed to analyze and quantify the roughness of the surface (both in the flat area of the samples and inside the pores). To evaluate surface roughness, the arithmetical mean deviation $\left(S_{a}\right)$ and the root mean square height $\left(\mathrm{S}_{\mathrm{q}}\right)$ were calculated.

\subsection{Cell Behavior Evaluation}

A preliminary study of the cellular behavior of superficially modified samples was carried out. MC3T3E1, which is a murine pre-osteoblast cell line (CRL-2593, from ATCC, Manassas, VA, USA), was used to analyze the potential influence of surface modified with femtosecond in the bone cells (morphology, cell adhesion, and proliferation) [61-65]. Routine passaging of the cell line was performed on $25 \mathrm{~cm}^{2}$ flasks with minimum essential medium (MEM), containing $10 \%$ fetal bovine serum plus antibiotics (100 U/mL penicillin and $100 \mathrm{mg} / \mathrm{mL}$ streptomycin sulfate) (Invitrogen). Autoclaved samples 
were carefully placed into a 24-well plate, and trypsinized osteoblasts cells were seeded at a cellular density of 30,000 cells $/ \mathrm{cm}^{2}$ per sample. Afterward, $800 \mu \mathrm{L}$ of prewarmed culture medium was added, and culture plates were kept at $37^{\circ} \mathrm{C}$ in a humidified $5 \% \mathrm{CO}_{2}$ atmosphere. The experiments were carried out at 4 days of culturing osteoblasts with osteogenic media ( $\alpha$-MEM medium supplemented with $10 \mathrm{mM}$ ascorbic acid (Merck, Darmstadt, Germany) and $\beta$-glycerophosphate (StemCell Technologies, Vancouver, BC, Canada) $50 \mu \mathrm{g} / \mathrm{mL}$ ). Scanning electron microscopy (SEM) was used to evaluate the cell behavior at 4 days. The samples were fixed in 10\% formalin, which was followed by a dehydration step with ethanolic solutions and coated by gold-coating using a sputter coater (Pelco 91000, Ted Pella, Redding, CA, USA). The images were obtained using a Jeol JSM-6330F scanning electron microscope (JEOL, Tokyo, Japan) with an acceleration voltage of $10 \mathrm{kV}$.

\section{Results and Discussion}

Figure 3 shows SEM images of the fully-dense and porous samples (100-200 $\mu \mathrm{m}$ and 355-500 $\mu \mathrm{m})$ before and after femtosecond laser irradiation (FS). The surface of the samples can be divided by the flat surface and the surface of the pores. Before irradiation, the flat part of all the samples has a smooth finish due to the polishing treatment. As for the pores, two types can be observed on the surface before irradiation. Small micro-pores are formed during the sintering process and the macro-pores inherent to the size ranges of the spacers are used in the space-holder technique. In addition, a pattern of micro-roughness can be observed inside the large pores. This pattern is a result of the inherent roughness of the surface of spacer particles, which is transferred to the titanium substrate during the compaction process. On the other hand, in the images after femtosecond laser irradiation, the effects produced by the laser treatment can be clearly observed. The surface of the samples is covered by clusters of micro-holes and micro-columns. These structures consist of groups of periodic micro-columns with pits between them. The pits have the shape of circular holes (like-craters of a volcano). The period of the laser-generated microstructure can be estimated from the magnified SEM images, giving average values under $10 \mu \mathrm{m}$. The clusters of micro-holes do not cover the entire surface. By modifying the processing parameters used for the irradiation, the spatial density of the micro-holes could be changed. If the energy per unit area were increased, the amount of surface covered by micro-holes would also be increased and vice versa. When looking at the image at a higher magnification, as shown in the close-ups at the right of Figure 3, it is observed that the entire surface is covered by a nanometric pattern. This pattern consists of laser-induced periodic surface structures (LIPSS), which appear when a surface is subject to ultra-short laser pulses. The structure is made up of periodic ripples aligned perpendicularly to the polarization of the laser beam. The period of the LIPSS structure is close to the wavelength of the laser, which is $1040 \mathrm{~nm}$ in this case.

Figure 4 shows SEM images of the flat areas and the interior of the pores. As shown in the images, the laser generated structures appeared both in the flat area and inside the macro-pores created from the space holders. The entire surface, including the areas with micro-features generated by the laser, is covered with nano-ripples. During laser processing, the laser fluence threshold required for the formation of micro-columns is larger than for the formation of LIPSS. The spatial profile of the laser beam has Gaussian shape and, therefore, the fluence is higher in the center of the beam than in the outer region. When the laser beam moves along the surface, the fluence at the region near the center of the beam is high enough to produce the formation of micro-columns. When the beam moves away, the outer region of the beam with a fluence below the threshold for micro-column formation but above the threshold for melting, creates the ripples over the already present microstructure, which explains the structures obtained in this work [51].

There is no appreciable difference between the textures obtained in the flat areas and in the areas inside the pores. This fact indicates that the energy deposited is roughly the same for the whole surface, despite the difference in height between the flat area and the region inside the pores. Although this is true for the optical system used in this work, another system with a more pronounced beam divergence 
could be more sensitive height changes in the topography. In that case, it may be necessary to adjust the focus position according to the height of the sample so that the result is homogeneous.

Figure 5 shows images of the samples obtained by confocal laser microscopy. The roughness parameters $S_{a}$ and $S_{q}$ obtained using this technique are summarized in Table 2. The roughness was measured before and after the femtosecond laser treatment for the whole surface of the samples. For the space-holder samples, the roughness of the flat surface between macro-pores was also measured.



Figure 3. Scanning electron microscopy (SEM) images of the surfaces before and after femtosecond laser irradiation. The close-up images (higher magnification) correspond to the flat surface of titanium that lies between the macro pores generated by the spacer. 

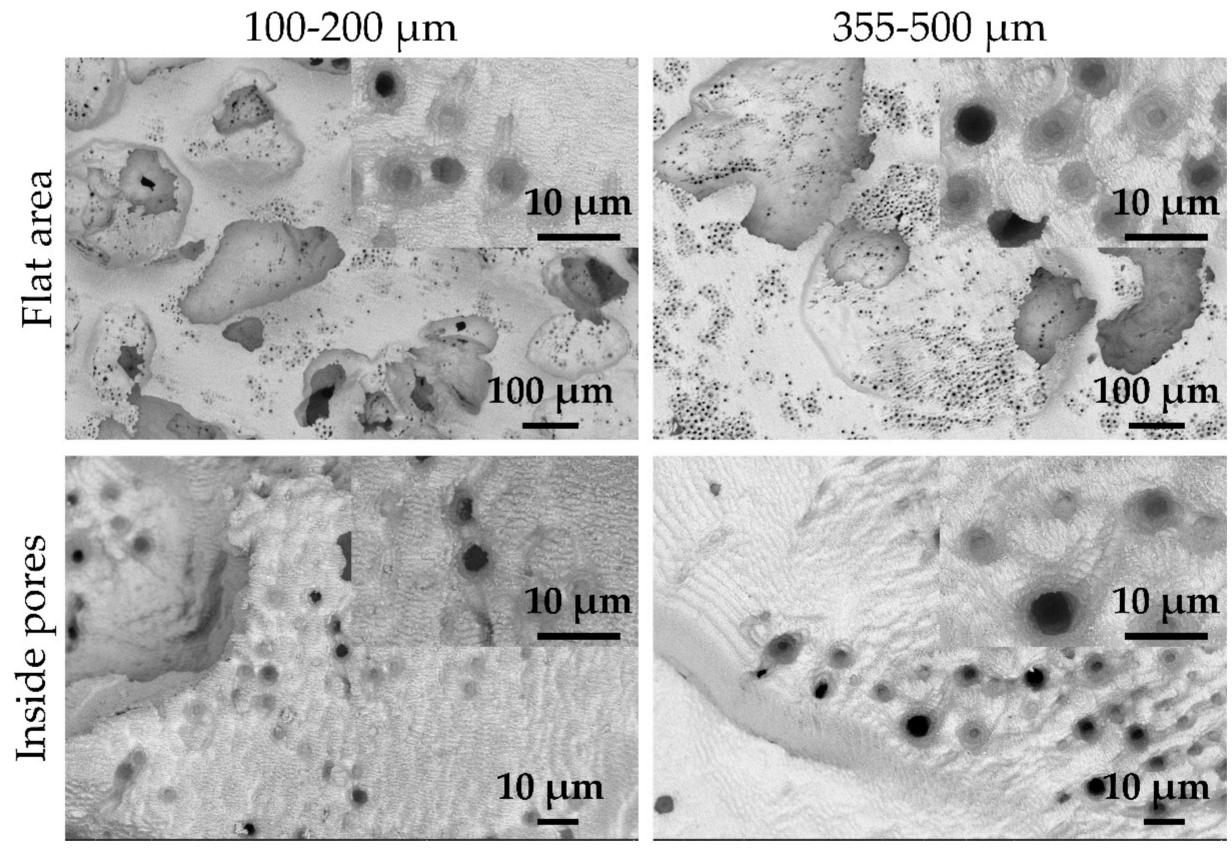

Figure 4. SEM (using the topography view configuration, it gathers both material and topographic contrast with the unique segmented in-lens backscattered electrons (BSE) detector (T1)) images of the titanium flat surfaces and walls of the macro pores after laser treatment. Note: Regardless of the area and type of porous substrate studied, a similar morphology of micro-holes and surface roughness patterns generated with irradiation can be observed in the inside images (more magnification).

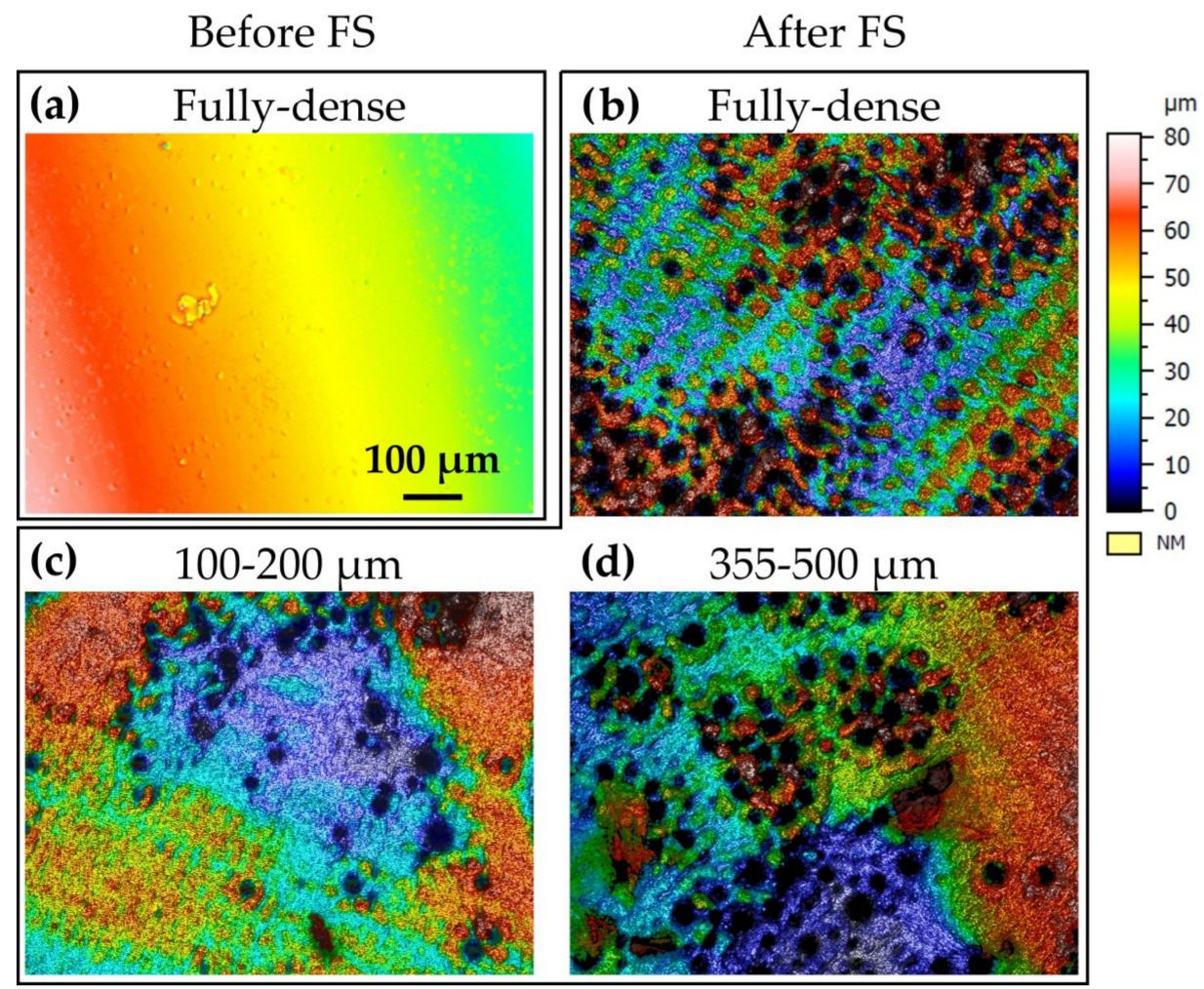

Figure 5. Confocal laser microscopy images of the modified titanium surface with femtosecond irradiation: (a) fully-dense sample before surface treatment, (b) modified surface of the fully-dense, (c) and (d) appearance of the irradiated titanium surface present between the macro-pores of sizes between 100-200 $\mu \mathrm{m}$ and 355-500 $\mu \mathrm{m}$, respectively. 
Table 2. Influence of the characteristics of the pores and the femtosecond laser irradiation on the surface roughness modification of the samples. The magnification of the measures was $10 \times$ and $100 \times$.

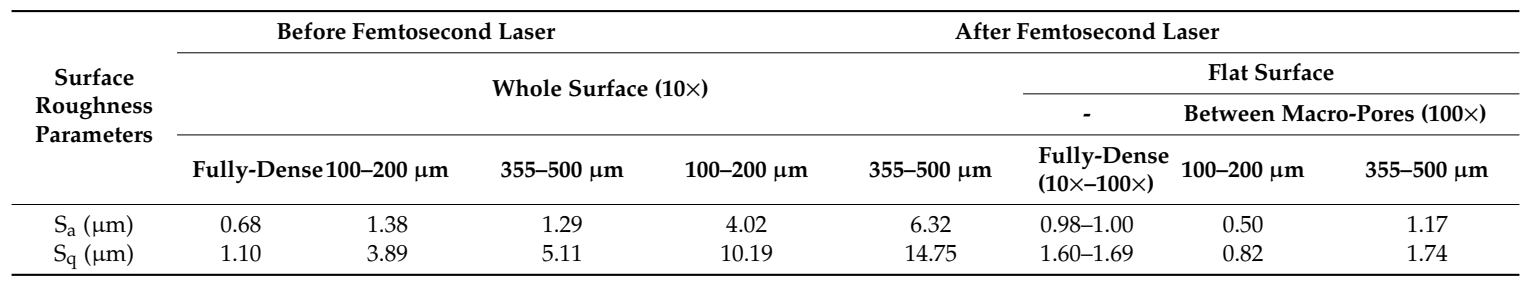

Before laser treatment, the fully dense sample presented very low roughness, with $S_{a}=0.68 \mu \mathrm{m}$, due to previous polishing. The porous samples had slightly higher roughness, with values of $S_{a}=1.38$ for the 100-200 $\mu \mathrm{m}$ sample and $S_{a}=1.29$ for the 355-500 $\mu \mathrm{m}$ sample. Since the flat surface of the porous samples is also predominantly smooth, the increase in roughness must be caused by the existence of the pores. Furthermore, in Figure 4, a roughness pattern can be seen on the surface of the interior of the pores, which also contributes to the increase of the roughness values. After laser irradiation, the roughness of all the samples was increased. The new values of roughness were $\mathrm{Sa}=0.98$ for the fully-dense sample, $S_{a}=4.02 \mu \mathrm{m}$ for the 100-200 $\mu \mathrm{m}$ sample, and $S_{a}=6.32$ for the 355-500 $\mu \mathrm{m}$ sample. The changes on the topography after the laser treatment can be clearly seen in the images of Figure 5. The laser irradiation produced a surface with heterogeneous height and a grainy texture. The heterogeneity of the color, as opposed to the untreated samples, is explained by the presence of nano-ripples all over the surface. The clusters of micro-holes generated during the laser treatment appear as circular areas with darker colors than their surroundings. The roughness was also measured at a higher magnification $(100 \times)$ for the fully dense surface and for the flat surface between macro-pores for the porous samples, which correspond to the areas shown in Figure 5. The resultant values were $S_{a}=1.00 \mu \mathrm{m}$ for the fully-dense sample, $S_{a}=0.50 \mu \mathrm{m}$ for the $100-200 \mu \mathrm{m}$ sample, and $S_{a}=1.17 \mu \mathrm{m}$ for the 355-500 $\mu \mathrm{m}$ sample. On these areas, the roughness is due only to femtosecond laser texturing. Since these topographies do not show large deviations from the mean surface, the $S_{a}$ value is lower than when the macro-pores are considered $\left(S_{a}=4.02 \mu \mathrm{m}\right.$ and $\left.S_{a}=6.32 \mu \mathrm{m}\right)$.

Figure 6 shows 3D confocal images of the samples after the laser treatment. The images correspond to the fully-dense $100-200 \mu \mathrm{m}$ and 355-500 $\mu \mathrm{m}$ samples from top to bottom. The images of the left column correspond to a magnification of $10 \times$ while the ones of the right correspond to a value of $50 \times$. In the fully-dense sample, the areas with laser-induced topography are composed of micro-pores (small black dots) and micro-pillars (orange/pink). According to the color levels used, this shows that the micropores are lower and the micro-pillars are higher than the flat area with a blue-yellow color. This indicates that the micro-pillars generated by the laser treatment are produced above the flat surface. This fact can also be observed in the porous samples where the micro-pillars have a pink color whose corresponding height is superior to the orange and yellow of the flat area. At the highest magnification, it can be seen how these regions form protrusions above the flat surface. As for the macro-pores, the depth and size of all the pores inspected is very uniform. They have a dark-blue/cyan color that indicates they are below the flat surface.

Image analysis (IA) was performed over the SEM images of the samples to calculate their porosity parameters. Since, after laser treatment, there are pores with different origins, they were divided and analyzed in three groups, as shown in Figure 7. The groups consisted of micro-pores associated with the femtosecond laser irradiation on the flat surface (red), macro-pores inherent to the spacer used (yellow), and micro-pores associated with the femtosecond laser irradiation on the walls inside the macro-pores (blue).

The porosity parameters measured before and after laser treatment are reported in Table 3. Before irradiation, the fully-dense sample presented low porosity, $\mathrm{P}_{\mathrm{T}}=1.6 \pm 0.3 \%$, caused by small micro-pores of $\mathrm{D}_{\mathrm{eq}}=5.9 \pm 0.2 \mu \mathrm{m}$ inherent to the sintering process. The porosity percentage for the $100-200 \mu \mathrm{m}$ and $355-500 \mu \mathrm{m}$ samples was $52.3 \mu \mathrm{m} \pm 1.2$ and $50.1 \mu \mathrm{m} \pm 1.0$, respectively, which are values close to 
the $50 \%$ design target. The diameter of the pores in these samples was $164 \mu \mathrm{m} \pm 28$ and $395 \mu \mathrm{m} \pm 34$. Therefore, it lies within the expected range for the spacers used. The shape factor of the pores was close to 1 for all the samples, which shows a high degree of circularity.

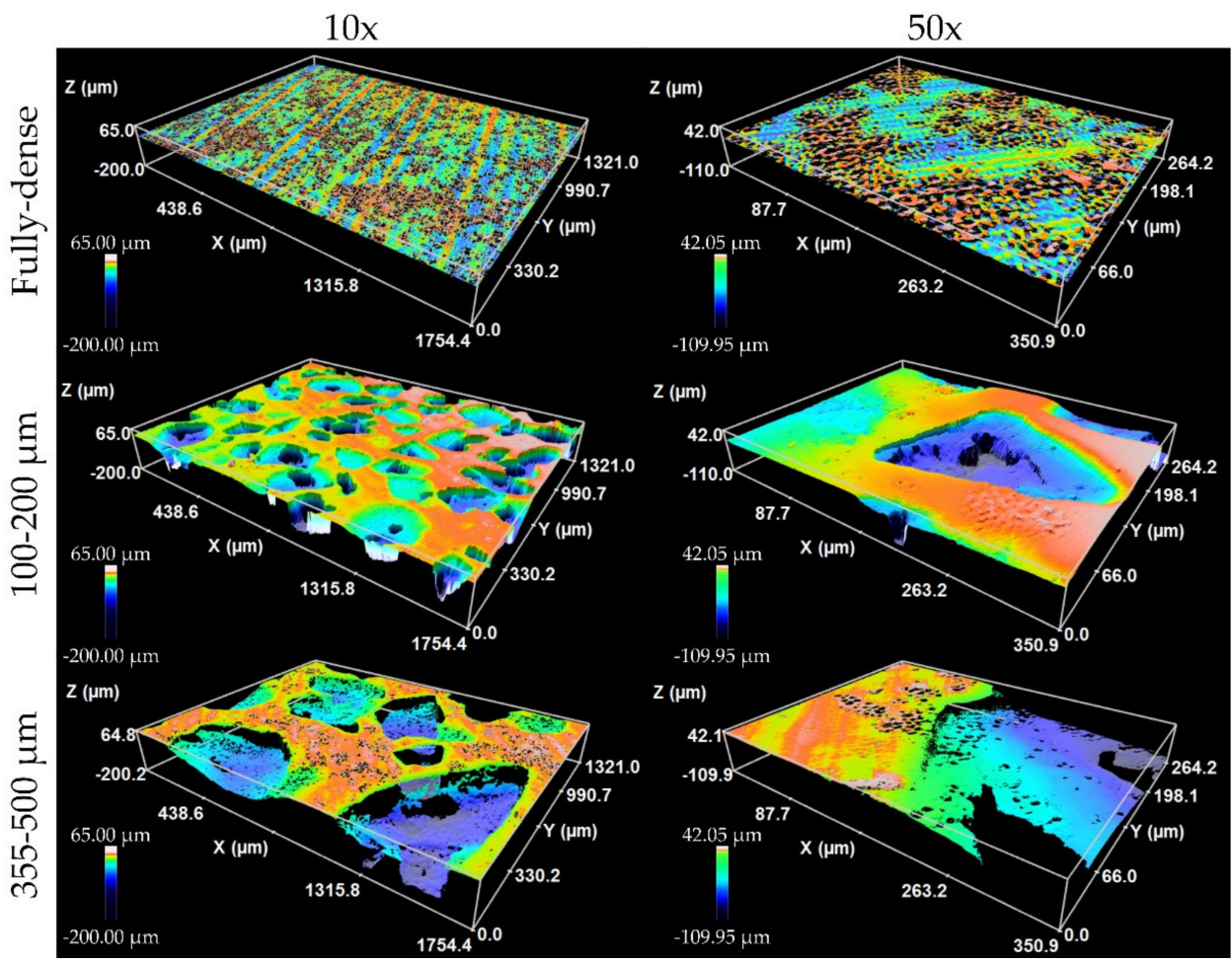

Figure 6. Confocal laser 3D images showing the distribution of macro and micro porosity. Sequence of colors from low to high height: black, dark blue, cyan, green, yellow, orange, and pink. Macro-pores are dark-blue/cyan, micro-pores are black, and micro-pillars are orange/pink.

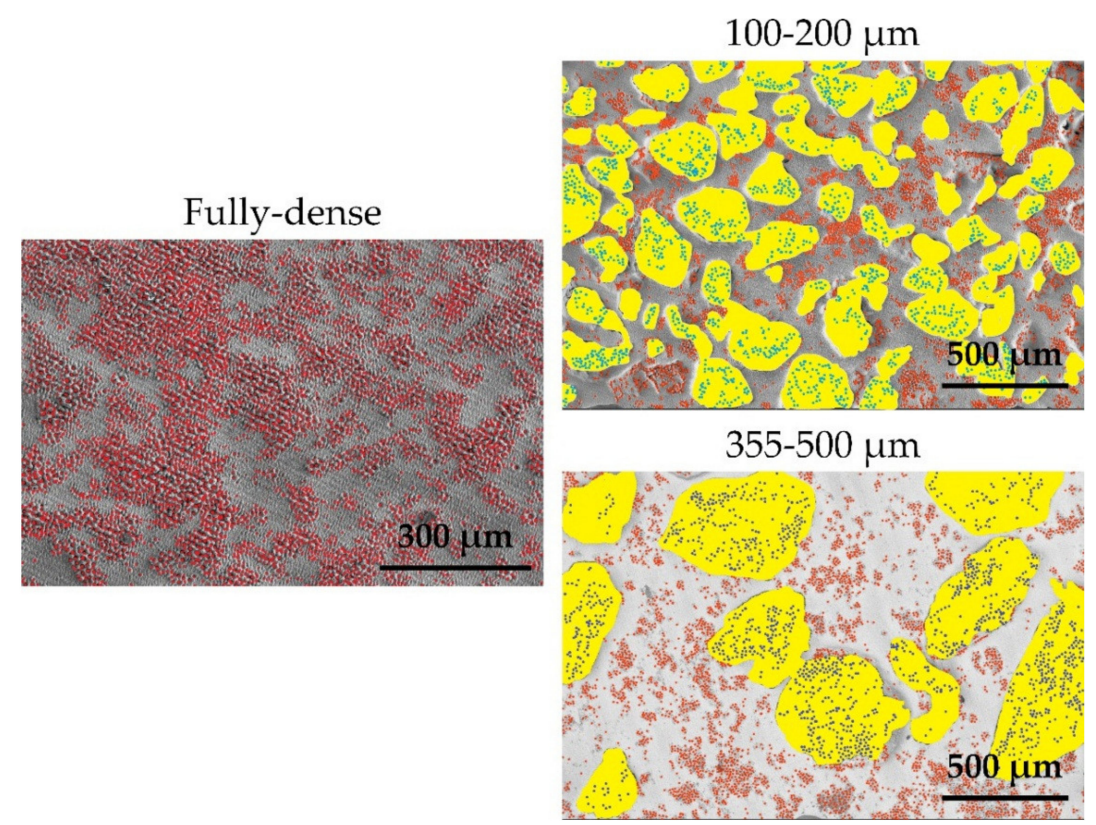

Figure 7. Image analysis of the modified discs. Note: in the images, different pore populations have been identified. The macro pores (spacer) have been colored yellow while the micro-pores inherent to laser treatment have been colored red (flat titanium surface) and blue (interior walls of the macro pores). 
Table 3. Porosity parameters measured by Image Analysis: total porosity $\left(P_{T}\right)$, the equivalent diameter $\left(D_{e q}\right)$, and the pore shape factor $\left(F_{f}\right)$. Note: ${ }^{*}$ Flat surface (between macro-pores) and + Inside of pores.

\begin{tabular}{|c|c|c|c|c|c|c|}
\hline \multirow{2}{*}{\multicolumn{2}{|c|}{ Porosity Parameters }} & \multirow{2}{*}{ Fully-Dense } & \multicolumn{4}{|c|}{ Spacer Size } \\
\hline & & & \multicolumn{2}{|c|}{$100-200 \mu \mathrm{m}$} & \multicolumn{2}{|c|}{$355-500 \mu \mathrm{m}$} \\
\hline \multirow{4}{*}{ Before FS } & \multirow{4}{*}{$\begin{array}{c}\mathrm{P}_{\mathrm{T}}(\%) \\
\mathrm{D}_{\mathrm{eq}}(\mu \mathrm{m}) \\
\mathrm{F}_{\mathrm{f}}\end{array}$} & $1.6 \pm 0.3$ & \multirow{3}{*}{\multicolumn{2}{|c|}{$\begin{array}{c}52.3 \pm 1.2 \\
164 \pm 28 \\
0.72\end{array}$}} & \multirow{3}{*}{\multicolumn{2}{|c|}{$\begin{array}{c}50.1 \pm 1.0 \\
395 \pm 34 \\
0.75\end{array}$}} \\
\hline & & $5.9 \pm 0.2$ & & & & \\
\hline & & 0.97 & & & & \\
\hline & & & $P_{\text {femto }}$ & $\mathbf{P}_{\text {spacer }}$ & $P_{\text {femto }}$ & $\mathbf{P}_{\text {spacer }}$ \\
\hline \multirow{2}{*}{ After FS } & $\mathrm{P}_{\mathrm{T}}(\%)$ & $25.6 \pm 0.9$ & $\begin{array}{l}4.4 \pm 0.7^{*} \\
0.9 \pm 0.3^{\dagger}\end{array}$ & $44.2 \pm 2.8$ & $\begin{array}{c}1.92 \pm 0.9^{*} \\
0.3 \pm 0.2^{+}\end{array}$ & $45.8 \pm 1.4$ \\
\hline & $\underset{F_{f}}{D_{\text {eq }}(\mu \mathrm{m})}$ & $\begin{array}{c}3.2 \pm 1.2 \\
0.74\end{array}$ & $\begin{array}{c}4.6 \pm 0.9 \\
0.63\end{array}$ & $\begin{array}{c}123 \pm 52 \\
0.34\end{array}$ & $\begin{array}{c}2.8 \pm 0.7 \\
0.70\end{array}$ & $\begin{array}{c}373 \pm 42 \\
0.35\end{array}$ \\
\hline
\end{tabular}

After irradiation, the porosity of the fully dense sample was clearly increased to a value of $\mathrm{P}_{\mathrm{T}}=25.6$ $\pm 0.9 \%$. The effect of the treatment on the percentage of porosity was less significant in the porous samples since the presence of macro-pores continued to be the dominant factor for determining total porosity, which maintained similar values despite being marginally lower than before the treatment. In these samples, the distribution of the laser-induced micro-holes was homogeneous over the entire studied area with a similar number of them being located within the macro-pores in the flat areas. The diameter of the micro-holes generated by the femtosecond laser was roughly similar for all the samples: $\mathrm{D}_{\text {eq }}=3.2 \pm 1.2 \mu \mathrm{m}, 4.6 \pm 0.9 \mu \mathrm{m}$, and $2.8 \pm 0.7 \mu \mathrm{m}$ for the fully-dense samples and 100-200 $\mu \mathrm{m}$ and $355-500 \mu \mathrm{m}$ for other samples. The micro-pores obtained by the laser treatment were generally smaller than the micro-pores from the sintering process, but they had a more irregular shape $\left(\mathrm{F}_{\mathrm{f}}=0.74\right.$, $0.63,0.70)$. The laser treatment also increased the irregularity of the walls of the macro-pores, reducing the shape factor of these pores from $F_{f}=0.72$ to $F_{f}=0.34$ for the 100-200 $\mu \mathrm{m}$ sample and from $F_{f}=0.75$ to $\mathrm{F}_{\mathrm{f}}=0.35$ for the $355-500 \mu \mathrm{m}$ sample.

According to the results obtained, a hierarchical triple structure was attained on the surface of the porous samples. This structure consists of macro-pores manufactured by the space-holder technique and micro-holes and nano-ripples produced by femtosecond laser irradiation. The characteristic sizes of the structures ranged from 150 to $300 \mu \mathrm{m}$ for the space-holder pores, around $3.5 \mu \mathrm{m}$ for the laser generated micro-pores, and under $1 \mu \mathrm{m}$ for the laser generated nano-ripples. All the structures coexist simultaneously in the same areas since the surface of each structure is covered by the smaller structures. The geometry of the global structure could be tuned by changing the parameters of the processes used to manufacture the sample. The number and size of the big macro-pores can be changed by modifying the total volume of the space holder solution and the size of space holder particles. The spatial density, i.e., the amount of micro-holes generated, could be changed by controlling the laser parameters. For instance, increasing laser fluence would also increase the amount of micro-holes generated on the surface. The flexibility of the laser technique would also allow controlling the area of application of the beam in case it was desired to generate multiple areas with a different morphology.

On the other hand, in this work, we can estimate Young's modulus and the elastic limit of porous implants from the results collected in Table 3 and by using Equations (1), (2), and (3) proposed in the literature $\left(\mathrm{E}_{\mathrm{N}}\right.$ (Nielsen equation) [66], $\mathrm{E}_{\mathrm{d}}$ (dynamic Young's modulus) [67], and $\sigma_{\mathrm{y}}$ [68]), which establish relationships between microstructural parameters (porosity and pore morphology) and mechanical behavior.

$$
\begin{gathered}
E_{d}=E_{T i} \cdot\left(e^{-0.02 \cdot P_{T}}\right)-0.03 \cdot E_{T i} \\
E_{N}=\frac{E_{T i} \cdot\left(1-\frac{P_{T}}{100}\right)^{2}}{1+\left(F_{f}-1\right) \cdot \frac{P_{T}}{100}}
\end{gathered}
$$


where $E_{T i}$ is the Young's modulus for bulk Ti CP-Grade IV ( 110 GPa [69]), $P_{T}$ is the percentage of total porosity of the sample, and $F_{f}$ is the shape factor.

$$
\frac{\sigma_{y}}{\sigma_{T i}}=\left(1.2018 \cdot e^{-0.043 \cdot P i}\right)
$$

where $\sigma_{T i}$ is the yield strength of bulk Ti CP-Grade IV ( 650 GPa [70]) and $P_{i}$ is the percentage of interconnected porosity of the sample.

Table 4 shows the values obtained with these equations for porous implants before and after the laser treatment. From these results, it is possible to indicate the yield strength does not depend on the surface treatment. In our materials, the triaxial distribution of stress in the bulk is not affected (porosity is the same). However, the new surface porosity may decrease the fatigue resistance of the implant, and there is an inverse relationship between the porosity and the Young's modulus of the material.

Table 4. Young's modulus $\left(\mathrm{E}_{\mathrm{N}}\right.$ and $\left.\mathrm{E}_{\mathrm{d}}\right)$ and the yield strength $\left(\sigma_{\mathrm{y}}\right)$ estimated for porous implants before and after FS.

\begin{tabular}{ccccc}
\hline \multirow{2}{*}{ Mechanical Properties } & \multirow{2}{*}{ Fully-Dense } & \multicolumn{2}{c}{ Spacer Size } \\
\cline { 3 - 5 } & & & $\mathbf{1 0 0 - 2 0 0} \boldsymbol{\mu \mathbf { m }}$ & $\mathbf{3 5 5 - 5 0 0 ~} \mathbf{m}$ \\
\hline \multirow{3}{*}{ Before FS } & $\mathrm{E}_{\mathrm{N}}(\mathrm{GPa})$ & $106.6 \pm 1.3$ & $29.3 \pm 2.7$ & $31.3 \pm 2.3$ \\
\cline { 2 - 5 } & $\mathrm{E}_{\mathrm{d}}(\mathrm{GPa})$ & $103.2 \pm 1.3$ & $35.4 \pm 1.9$ & $37.1 \pm 1.6$ \\
& $\sigma_{\mathrm{y}}(\mathrm{MPa})$ & 738 & 95 & 118 \\
\hline \multirow{3}{*}{ After FS } & $\mathrm{E}_{\mathrm{N}}(\mathrm{GPa})$ & $65.2 \pm 3.1$ & $41.7 \pm 7.0$ & $43.2 \pm 6.3$ \\
& $\mathrm{E}_{\mathrm{d}}(\mathrm{GPa})$ & $62.6 \pm 2.6$ & $37.6 \pm 4.7$ & $38.8 \pm 4.2$ \\
& $\sigma_{\mathrm{y}}(\mathrm{MPa})$ & 738 & 96 & 118 \\
\hline
\end{tabular}

Lastly, Figure 8 shows a preliminary result of the ongoing study of the evaluation of the bone environment in vitro. In particular, it is compared completely dense (before femtosecond treatment) with porous titanium substrate (after surface modification). In these experiences, MC3T3E1 used a murine pre-osteoblastic cell line (CRL-2593, from ATCC, Maassas, VA, USA) to analyze the effect of porosity and surface treatment on cell metabolism and viability during the process of cell adhesion and proliferation. The results indicate a clear improvement in cell proliferation in the modified disc. Here, the MC3T3 cell monolayer was found. Osteoblast cells were marked with a yellow arrow and a nucleus was marked with red asterisks in the images. The completely dense ones had a cellular cytoskeleton extended at the edges of the sample while the osteoblastic cells covered the internal walls of the macro-pores inert to the use of the spacer. The cells adhere through filopodia (fine cellular projections). Furthermore, osteoblast growing on a controlled, fully dense surface presented lower filopodia protrusions, which are essential cellular structures during the cell adhesion process. 

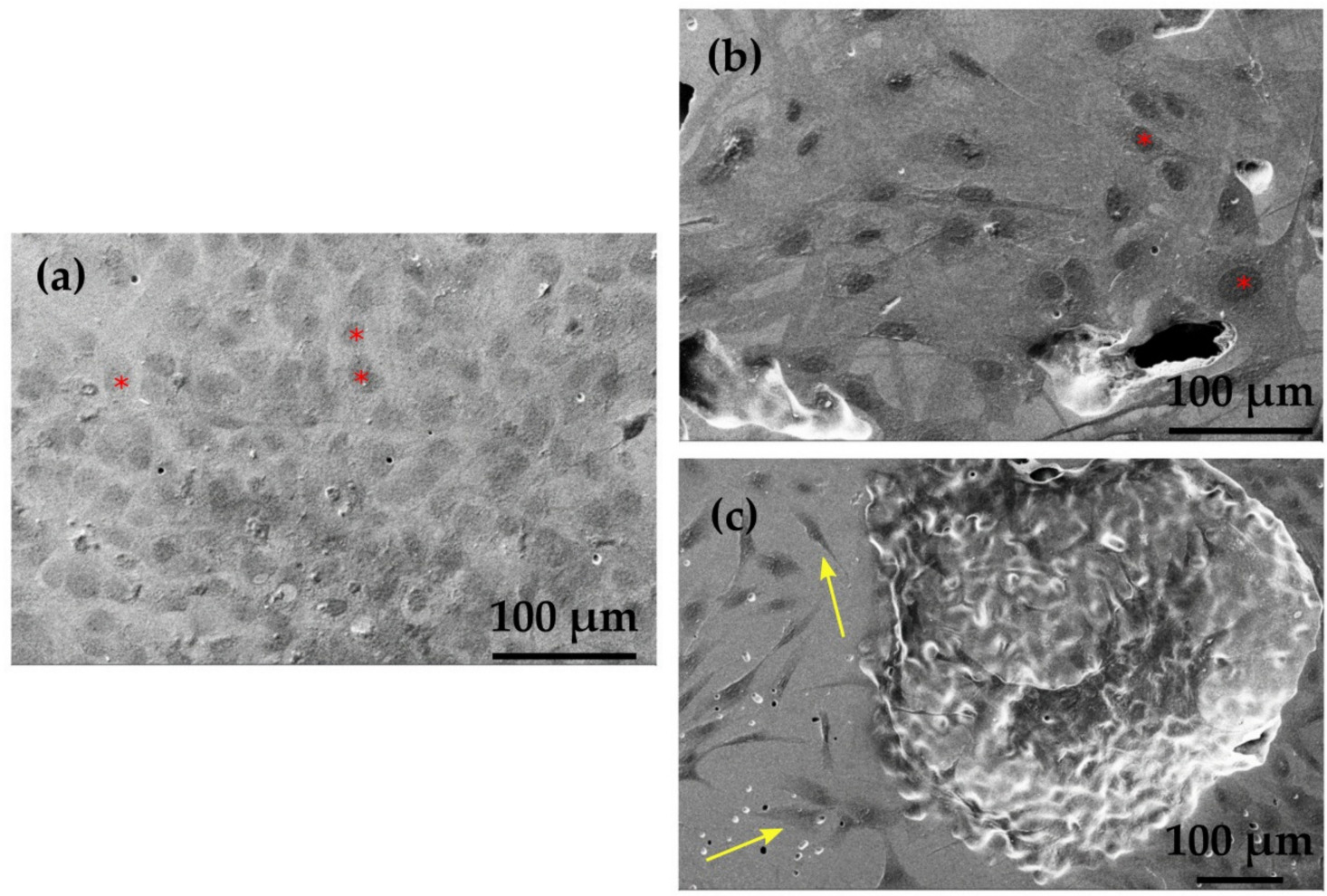

Figure 8. SEM images of MC3T3 cell morphology growing (four days incubation) on the (a) surface of virgin fully-dense sample, (b) surface, and (c) within the macro-pores of porous titanium substrate (after femtosecond laser treatment). The MC3T3 cell (yellow arrow) and the nucleus cell (red asterisks) are indicated in the images.

\section{Conclusions}

This work evaluated the ability to create hierarchical micro-nano-structures on the surface of fully-dense and porous Ti CP substrates for bone replacement using a femtosecond laser system.

Femtosecond laser micromachining allows different structures to be obtained on the surface of metals, which range from a nanoscale to a microscale size. The influence that the different processing parameters have on the formation of the surface structures is complex. However, all these parameters influence the total amount of energy deposited on the surface and the number of laser spots per unit area. In this work, using these factors as a basis of a parametric study helped us obtain the set of parameters associated with the desired structures.

The laser texturing process generated clusters of micro-holes and micro-columns and periodic nanometric structures across the whole surface. In the porous samples, the laser-induced structures appeared both on the flat surface and inside the macro-pores. The structures obtained were similar for all types of substrates analyzed. Surface roughness generally increased for all the samples after the treatment due to the changes in the surface topography.

Image analysis of the samples revealed that the laser-induced micro-pores had a characteristic size slightly smaller than the micro-pores inherent to the sintering process, but with a more irregular shape. The effect of the treatment on total porosity was more prominent in the dense sample, which underwent a significant increase in value. In the porous samples, the change in total porosity was attenuated by the presence of the macro-pores. However, laser treatment increased the irregularity of the already present macro-pores.

Modifying the surface with femtosecond does not compromise the mechanical strength of porous titanium substrates, but a decrease in the elastic modulus is observed in the fully dense sample.

Preliminary results of bone evaluation in vitro show a clear improvement in cell proliferation on the surface of the modified sample. 
The approach presented in this work allows combining the biomechanical advantages of a porous substrate (stiffness and yield strength) and the bio-functional behavior of a modified surface (bone ingrowth and osseointegration) to improve the success of titanium implants.

The versatility and high precision of the laser as a micro-machining tool allow for treating complex surfaces. In this sense, the authors have begun to study the potential application of the approach used in this work for the design and manufacture of porous cylindrical dental implants and the modification of their surface using the femtosecond laser system.

Author Contributions: Conceptualization, project administration, supervision, methodology, J.M.A., V.A., and Y.T. Investigation, formal analysis, validation, Á.R., P.T., J.M.A., M.J.T., and M.G. Discussion and writing-original draft preparation, all the authors. All authors have read and agreed to the published version of the manuscript.

Funding: The regional government from Andalusia through FEDER-Junta de Andalucía Research Project US-1259771, (Modeling and implementation of the freeze casting technique: gradients of porosity with a tribomechanical equilibrium and electro-stimulated cellular behavior) funded this research.

Acknowledgments: The authors also thank laboratory technicians Jesús Pinto and Mercedes Sánchez for their technical support.

Conflicts of Interest: The authors declare no conflict of interest.

\section{References}

1. Khorasani, A.M.; Goldberg, M.; Doeven, E.H.; Littlefair, G. Titanium in biomedical applications-properties and fabrication: a review. J. Biomater. Tissue Eng. 2015, 5, 593-619. [CrossRef]

2. Kaur, M.; Singh, K. Review on titanium and titanium based alloys as biomaterials for orthopaedic applications. Mater. Sci. Eng. C 2019, 102, 844-862. [CrossRef] [PubMed]

3. Niinomi, M.; Liu, Y.; Nakai, M.; Liu, H.; Li, H. Biomedical titanium alloys with Young's moduli close to that of cortical bone. Regen. Biomater. 2016, 3, 173-185. [CrossRef] [PubMed]

4. Krishna, B.V.; Bose, S.; Bandyopadhyay, A. Low stiffness porous Ti structures for load-bearing implants. Acta Biomater. 2007, 3, 997-1006. [CrossRef]

5. Pałka, K.; Pokrowiecki, R. Porous Titanium implants: A review. Adv. Eng. Mater. 2018, 20, 1700648. [CrossRef]

6. Gristina, A.G. Biomaterial-centered infection: microbial adhesion versus tissue integration. Science 1987, 237, 1588-1595. [CrossRef]

7. Neoh, K.G.; Hu, X.; Zheng, D.; Kang, E.T. Balancing osteoblast functions and bacterial adhesion on functionalized titanium surfaces. Biomaterials 2012, 33, 2813-2822. [CrossRef]

8. Cordeiro, J.M.; Barão, V.A. Is there scientific evidence favoring the substitution of commercially pure titanium with titanium alloys for the manufacture of dental implants? Mater. Sci. Eng. C 2017, 71, 1201-1215. [CrossRef]

9. Niinomi, M.; Narushima, T.; Nakai, M. Niobium Biomaterials. In Advances in Metallic Biomaterials: Tissues, Materials and Biological Reactions; Springer: Berlin/Heidelberg, Germany, 2015; pp. 245-272.

10. Naebe, M.; Shirvanimoghaddam, K. Functionally graded materials: A review of fabrication and properties. Appl. Mater. Today 2016, 5, 223-245. [CrossRef]

11. Wu, S.; Liu, X.; Yeung, K.W.; Liu, C.; Yang, X. Biomimetic porous scaffolds for bone tissue engineering. Mater. Sci. Eng., $R$ 2014, 80, 1-36. [CrossRef]

12. Trueba, P.; Chicardi, E.; Rodríguez-Ortiz, J.; Torres, Y. Development and implementation of a sequential compaction device to obtain radial graded porosity cylinders. J. Manuf. Process. 2020, 50, 142-153. [CrossRef]

13. Wang, H.; Pieper, J.; Peters, F.; van Blitterswijk, C.A.; Lamme, E.N. Synthetic scaffold morphology controls human dermal connective tissue formation. J. Biomed. Mater. Res. Part Off. J. Soc. Biomater. Jpn. Soc. Biomater. Aust. Soc. Biomater. Korean Soc. Biomater. 2005, 74, 523-532. [CrossRef] [PubMed]

14. Xu, J.; Weng, X.-J.; Wang, X.; Huang, J.-Z.; Zhang, C.; Muhammad, H.; Ma, X.; Liao, Q.-D. Potential use of porous titanium-niobium alloy in orthopedic implants: preparation and experimental study of its biocompatibility in vitro. PloS One 2013, 8, e79289. [CrossRef] [PubMed] 
15. Teixeira, L.; Crippa, G.; Lefebvre, L.-P.; De Oliveira, P.; Rosa, A.; Beloti, M. The influence of pore size on osteoblast phenotype expression in cultures grown on porous titanium. Int. J. Oral Maxillofac. Surg. 2012, 41, 1097-1101. [CrossRef]

16. Taniguchi, N.; Fujibayashi, S.; Takemoto, M.; Sasaki, K.; Otsuki, B.; Nakamura, T.; Matsushita, T.; Kokubo, T.; Matsuda, S. Effect of pore size on bone ingrowth into porous titanium implants fabricated by additive manufacturing: an in vivo experiment. Mater. Sci. Eng. C 2016, 59, 690-701. [CrossRef]

17. Mavrogenis, A.; Dimitriou, R.; Parvizi, J.; Babis, G. Biology of implant osseointegration. J. Musculoskelet. Neuron. Interact 2009, 9, 61-71.

18. De Vasconcellos, L.M.R.; Carvalho, Y.R.; do Prado, R.F.; de Vasconcellos, L.G.O.; de Alencastro Graça, M.L.; Cairo, C.A.A. Porous Titanium by Powder Metallurgy for Biomedical Application: Characterization, Cell Citotoxity and in Vivo Tests of Osseointegration. In Biomedical Engineering: Technical Applications in Medicine; InTech: Rijeka, Croatia, 2012; pp. 47-74.

19. Ehrenfest, D.M.D.; Coelho, P.G.; Kang, B.-S.; Sul, Y.-T.; Albrektsson, T. Classification of osseointegrated implant surfaces: materials, chemistry and topography. Trends Biotechnol. 2010, 28, 198-206. [CrossRef]

20. Ibrahim, M.Z.; Sarhan, A.A.; Yusuf, F.; Hamdi, M. Biomedical materials and techniques to improve the tribological, mechanical and biomedical properties of orthopedic implants-a review article. J. Alloys Compd. 2017, 714, 636-667. [CrossRef]

21. Brunette, D.M.; Tengvall, P.; Textor, M.; Thomsen, P. Titanium in Medicine: Material Science, Surface Science, Engineering, Biological Responses and Medical Applications; Springer Science \& Business Media: Berlin/Heidelberg, Germany, 2012.

22. Coelho, P.G.; Granjeiro, J.M.; Romanos, G.E.; Suzuki, M.; Silva, N.R.; Cardaropoli, G.; Thompson, V.P.; Lemons, J.E. Basic research methods and current trends of dental implant surfaces. J. Biomed. Mater. Res. Part B Appl. Biomater. Off. J. Soc. Biomater. Jpn. Soc. Biomater. Aust. Soc. Biomater. Korean Soc. Biomater. 2009, 88, 579-596. [CrossRef]

23. Wennerberg, A.; Albrektsson, T. Effects of titanium surface topography on bone integration: a systematic review. Clin. Oral Implant. Res. 2009, 20, 172-184. [CrossRef]

24. Butz, F.; Aita, H.; Wang, C.; Ogawa, T. Harder and stiffer bone osseointegrated to roughened titanium. J. Dent. Res. 2006, 85, 560-565. [CrossRef] [PubMed]

25. Bornstein, M.M.; Schmid, B.; Belser, U.C.; Lussi, A.; Buser, D. Early loading of non-submerged titanium implants with a sandblasted and acid-etched surface: 5-year results of a prospective study in partially edentulous patients. Clin. Oral Implant. Res. 2005, 16, 631-638. [CrossRef] [PubMed]

26. Herrero-Climent, M.; Lázaro, P.; Rios, J.V.; Lluch, S.; Marqués, M.; Guillem-Martí, J.; Gil, F. Influence of acid-etching after grit-blasted on osseointegration of titanium dental implants: in vitro and in vivo studies. J. Mater. Sci. Mater. Med. 2013, 24, 2047-2055. [CrossRef] [PubMed]

27. Kim, M.-J.; Kim, C.-W.; Lim, Y.-J.; Heo, S.-J. Microrough titanium surface affects biologic response in MG63 osteoblast-like cells. J. Biomed. Mater. Res. A 2006, 79, 1023-1032. [CrossRef]

28. Lossdörfer, S.; Schwartz, Z.; Wang, L.; Lohmann, C.; Turner, J.; Wieland, M.; Cochran, D.L.; Boyan, B. Microrough implant surface topographies increase osteogenesis by reducing osteoclast formation and activity. J. Biomed. Mater. Res. Part Off. J. Soc. Biomater. Jpn. Soc. Biomater. Aust. Soc. Biomater. Korean Soc. Biomater. 2004, 70, 361-369. [CrossRef]

29. Buser, D.; Schenk, R.; Steinemann, S.; Fiorellini, J.; Fox, C.; Stich, H. Influence of surface characteristics on bone integration of titanium implants. A histomorphometric study in miniature pigs. J. Biomed. Mater. Res. 1991, 25, 889-902. [CrossRef]

30. Rønold, H.J.; Ellingsen, J.E. Effect of micro-roughness produced by TiO2 blasting — tensile testing of bone attachment by using coin-shaped implants. Biomaterials 2002, 23, 4211-4219. [CrossRef]

31. Deyneka-Dupriez, N.; Kocdemir, B.; Herr, U.; Fecht, H.-J.; Wilke, H.-J.; Claes, L. Interfacial shear strength of titanium implants in bone is significantly improved by surface topographies with high pit density and microroughness. J. Biomed. Mater. Res. Part B Appl. Biomater. Off. J. Soc. Biomater. Jpn. Soc. Biomater. Aust. Soc. Biomater. Korean Soc. Biomater. 2007, 82, 305-312. [CrossRef]

32. Dalby, M.J.; Gadegaard, N.; Tare, R.; Andar, A.; Riehle, M.O.; Herzyk, P.; Wilkinson, C.D.; Oreffo, R.O. The control of human mesenchymal cell differentiation using nanoscale symmetry and disorder. Nat. Mater. 2007, 6, 997. [CrossRef] 
33. Mendonça, G.; Mendonça, D.B.; Aragao, F.J.; Cooper, L.F. Advancing dental implant surface technology-from micron-to nanotopography. Biomaterials 2008, 29, 3822-3835. [CrossRef]

34. Biggs, M.J.; Richards, R.; Gadegaard, N.; Wilkinson, C.; Dalby, M. Regulation of implant surface cell adhesion: Characterization and quantification of S-phase primary osteoblast adhesions on biomimetic nanoscale substrates. J. Orthop. Res. 2007, 25, 273-282. [CrossRef] [PubMed]

35. De Oliveira, P.T.; Nanci, A. Nanotexturing of titanium-based surfaces upregulates expression of bone sialoprotein and osteopontin by cultured osteogenic cells. Biomaterials 2004, 25, 403-413. [CrossRef]

36. Fiedler, J.; Özdemir, B.; Bartholomä, J.; Plettl, A.; Brenner, R.E.; Ziemann, P. The effect of substrate surface nanotopography on the behavior of multipotnent mesenchymal stromal cells and osteoblasts. Biomaterials 2013, 34, 8851-8859. [CrossRef]

37. Salou, L.; Hoornaert, A.; Louarn, G.; Layrolle, P. Enhanced osseointegration of titanium implants with nanostructured surfaces: an experimental study in rabbits. Acta Biomater. 2015, 11, 494-502. [CrossRef] [PubMed]

38. García, A.J.; Reyes, C. Bio-adhesive surfaces to promote osteoblast differentiation and bone formation. J. Dent. Res. 2005, 84, 407-413. [CrossRef] [PubMed]

39. Devgan, S.; Sidhu, S.S. Evolution of surface modification trends in bone related biomaterials: A review. Mater. Chem. Phys. 2019, 233, 68-78. [CrossRef]

40. Wennerberg, A.; Jimbo, R.; Stübinger, S.; Obrecht, M.; Dard, M.; Berner, S. Nanostructures and hydrophilicity influence osseointegration: a biomechanical study in the rabbit tibia. Clin. Oral Implants Res. 2014, 25, 1041-1050. [CrossRef]

41. Le Guéhennec, L.; Soueidan, A.; Layrolle, P.; Amouriq, Y. Surface treatments of titanium dental implants for rapid osseointegration. Dent. Mater. 2007, 23, 844-854. [CrossRef]

42. Gittens, R.A.; McLachlan, T.; Olivares-Navarrete, R.; Cai, Y.; Berner, S.; Tannenbaum, R.; Schwartz, Z.; Sandhage, K.H.; Boyan, B.D. The effects of combined micron-/submicron-scale surface roughness and nanoscale features on cell proliferation and differentiation. Biomaterials 2011, 32, 3395-3403. [CrossRef]

43. Huang, Q.; Elkhooly, T.A.; Liu, X.; Zhang, R.; Yang, X.; Shen, Z.; Feng, Q. Effects of hierarchical micro/nano-topographies on the morphology, proliferation and differentiation of osteoblast-like cells. Colloids Surf. B Biointerfaces 2016, 145, 37-45. [CrossRef]

44. Zhao, L.; Mei, S.; Chu, P.K.; Zhang, Y.; Wu, Z. The influence of hierarchical hybrid micro/nano-textured titanium surface with titania nanotubes on osteoblast functions. Biomaterials 2010, 31, 5072-5082. [CrossRef] [PubMed]

45. Ferraris, S.; Bobbio, A.; Miola, M.; Spriano, S. Micro-and nano-textured, hydrophilic and bioactive titanium dental implants. Surf. Coat. Technol. 2015, 276, 374-383. [CrossRef]

46. Vilar, R. Laser Surface Modification of Biomaterials: Techniques and Applications; Woodhead Publishing: Duxford, UK, 2016.

47. Gaggl, A.; Schultes, G.; Müller, W.; Kärcher, H. Scanning electron microscopical analysis of laser-treated titanium implant surfaces-a comparative study. Biomaterials 2000, 21, 1067-1073. [CrossRef]

48. Sugioka, K.; Meunier, M.; Piqué, A. Laser precision microfabrication; Springer: Berlin/Heidelberg, Germany, 2010; Volume 135.

49. Ahmmed, K.; Grambow, C.; Kietzig, A.-M. Fabrication of micro/nano structures on metals by femtosecond laser micromachining. Micromachines 2014, 5, 1219-1253. [CrossRef]

50. Vorobyev, A.; Guo, C. Femtosecond laser structuring of titanium implants. Appl. Surf. Sci. 2007, 253, 7272-7280. [CrossRef]

51. Oliveira, V.; Ausset, S.; Vilar, R. Surface micro/nanostructuring of titanium under stationary and non-stationary femtosecond laser irradiation. Appl. Surf. Sci. 2009, 255, 7556-7560. [CrossRef]

52. Nayak, B.; Gupta, M.; Kolasinski, K. Formation of nano-textured conical microstructures in titanium metal surface by femtosecond laser irradiation. Appl. Phys. A 2008, 90, 399-402. [CrossRef]

53. Dumas, V.; Guignandon, A.; Vico, L.; Mauclair, C.; Zapata, X.; Linossier, M.T.; Bouleftour, W.; Granier, J.; Peyroche, S.; Dumas, J.-C.; et al. Femtosecond laser nano/micro patterning of titanium influences mesenchymal stem cell adhesion and commitment. Biomed. Mater. 2015, 10, 055002. [CrossRef]

54. Bush, J.R.; Nayak, B.K.; Nair, L.S.; Gupta, M.C.; Laurencin, C.T. Improved bio-implant using ultrafast laser induced self-assembled nanotexture in titanium. J. Biomed. Mater. Res. B Appl. Biomater. 2011, 97, 299-305. [CrossRef] 
55. Cunha, A.; Zouani, O.F.; Plawinski, L.; Botelho do Rego, A.M.; Almeida, A.; Vilar, R.; Durrieu, M.-C. Human mesenchymal stem cell behavior on femtosecond laser-textured Ti-6Al-4V surfaces. Nanomed. 2015, 10, 725-739. [CrossRef]

56. Raimbault, O.; Benayoun, S.; Anselme, K.; Mauclair, C.; Bourgade, T.; Kietzig, A.-M.; Girard-Lauriault, P.-L.; Valette, S.; Donnet, C. The effects of femtosecond laser-textured Ti-6Al-4V on wettability and cell response. Mater. Sci. Eng. C 2016, 69, 311-320. [CrossRef] [PubMed]

57. Lee, B.E.; Exir, H.; Weck, A.; Grandfield, K. Characterization and evaluation of femtosecond laser-induced sub-micron periodic structures generated on titanium to improve osseointegration of implants. Appl. Surf. Sci. 2018, 441, 1034-1042. [CrossRef]

58. Li, B.; Li, H.; Huang, L.; Ren, N.; Kong, X. Femtosecond pulsed laser textured titanium surfaces with stable superhydrophilicity and superhydrophobicity. Appl. Surf. Sci. 2016, 389, 585-593. [CrossRef]

59. Cunha, A.; Serro, A.P.; Oliveira, V.; Almeida, A.; Vilar, R.; Durrieu, M.-C. Wetting behaviour of femtosecond laser textured Ti-6Al-4V surfaces. Appl. Surf. Sci. 2013, 265, 688-696. [CrossRef]

60. Cunha, A.; Elie, A.-M.; Plawinski, L.; Serro, A.P.; do Rego, A.M.B.; Almeida, A.; Urdaci, M.C.; Durrieu, M.-C.; Vilar, R. Femtosecond laser surface texturing of titanium as a method to reduce the adhesion of Staphylococcus aureus and biofilm formation. Appl. Surf. Sci. 2016, 360, 485-493. [CrossRef]

61. Torres, Y.; Rodríguez, J.; Arias, S.; Echeverry, M.; Robledo, S.; Amigo, V.; Pavón, J. Processing, characterization and biological testing of porous titanium obtained by space-holder technique. J. Mater. Sci. 2012, 47, 6565-6576. [CrossRef]

62. Muñoz, S.; Pavón, J.; Rodríguez-Ortiz, J.; Civantos, A.; Allain, J.P.; Torres, Y. On the influence of space holder in the development of porous titanium implants: Mechanical, computational and biological evaluation. Mater. Charact. 2015, 108, 68-78. [CrossRef]

63. Civantos, A.; Domínguez, C.; Pino, R.J.; Setti, G.; Pavón, J.J.; Martínez-Campos, E.; Garcia, F.J.G.; Rodríguez, J.A.; Allain, J.P.; Torres, Y. Designing bioactive porous titanium interfaces to balance mechanical properties and in vitro cells behavior towards increased osseointegration. Surf. Coat. Technol. 2019, 368, 162-174. [CrossRef]

64. Civantos, A.; Allain, J.P.; Pavón, J.J.; Shetty, A.; El-Atwani, O.; Walker, E.; Arias, S.L.; Gordon, E.; Rodríguez-Ortiz, J.A.; Chen, M.; et al. Directed Irradiation Synthesis as an Advanced Plasma Technology for Surface Modification to Activate Porous and "as-received" Titanium Surfaces. Metals 2019, 9, 1349. [CrossRef]

65. Civantos, A.; Giner, M.; Trueba, P.; Lascano, S.; Montoya-García, M.-J.; Arévalo, C.; Vázquez, M.Á.; Allain, J.P.; Torres, Y. In Vitro Bone Cell Behavior on Porous Titanium Samples: Influence of Porosity by Loose Sintering and Space Holder Techniques. Metals 2020, 10, 696. [CrossRef]

66. Nielsen, L.F. On strength of porous material: Simple systems and densified systems. Mater. Struct. 1998, 31, 651-661. [CrossRef]

67. Lascano, S.; Arévalo, C.; Montealegre-Melendez, I.; Muñoz, S.; Rodriguez-Ortiz, J.A.; Trueba, P.; Torres, Y. Porous titanium for biomedical applications: Evaluation of the conventional powder metallurgy frontier and space-holder technique. Appl. Sci. 2019, 9, 982. [CrossRef]

68. Trueba, P.; Beltrán, A.M.; Bayo, J.M.; Rodríguez-Ortiz, J.A.; Larios, D.F.; Alonso, E.; Dunand, D.C.; Torres, Y. Porous Titanium Cylinders Obtained by the Freeze-Casting Technique: Influence of Process Parameters on Porosity and Mechanical Behavior. Metals 2020, 10, 188. [CrossRef]

69. Shen, H.; Brinson, L.C. Finite element modeling of porous titanium. Int. J. Solids Struct. 2007, 44, 320-335. [CrossRef]

70. Imwinkelried, T. Mechanical properties of open-pore titanium foam. J. Biomed. Mater. Res. A 2007, 81, 964-970. [CrossRef]

(C) 2020 by the authors. Licensee MDPI, Basel, Switzerland. This article is an open access article distributed under the terms and conditions of the Creative Commons Attribution (CC BY) license (http://creativecommons.org/licenses/by/4.0/). 